\title{
Effects of $\mathrm{Cl}$ channel blockers on Ca-activated chloride and potassium currents in smooth muscle cells from rabbit portal vein
}

\author{
R.C. Hogg, Q. Wang \& 'W.A. Large \\ Department of Pharmacology and Clinical Pharmacology, St. George's Hospital Medical School, Cranmer Terrace, \\ London SW17 0RE
}

1 The effects of some chloride channel antagonists were studied on the calcium-activated chloride current $\left(I_{\mathrm{Cl}(\mathrm{Ca})}\right)$ in smooth muscle cells from the rabbit portal vein with the perforated patch technique. 2 4-Acetamido-4'-isothiocyanatostilbene-2,2'-disulphonic acid (SITS) and 4,4'-diisothiocyanato-stilbene-2,2'-disulphonic acid (DIDS) reduced the amplitude of spontaneous transient inward currents (STICs, calcium-activated chloride currents) in a concentration-dependent manner. The concentrations required to reduce the amplitude by $50 \%\left(\mathrm{IC}_{50}\right)$ of STICs were $2.1 \times 10^{-4} \mathrm{M}$ and $6.4 \times 10^{-4} \mathrm{M}$ for DIDS and SITS, respectively. This effect was not voltage-dependent.

3 The time constant of decay of STICs $(\tau)$, which is voltage-dependent, was increased by about $30 \%$ by SITS and decreased by about $20 \%$ by DIDS. The effect of DIDS and SITS on $\tau$ was similar at holding potentials of -50 and $+50 \mathrm{mV}$.

4 These compounds did not modify the characteristics of spontaneous transient outward currents (STOCs, calcium-activated potassium currents).

5 DIDS and SITS decreased the amplitude of $I_{\mathrm{CI}(\mathrm{Ca})}$ evoked by noradrenaline and caffeine less potently than STICs with $\mathrm{IC}_{50}$ values of $7.5 \times 10^{-4} \mathrm{M}$ and $1.8 \times 10^{-3} \mathrm{M}$, respectively.

6 DIDS and SITS increased the calcium-activated potassium current $\left(I_{\mathrm{K}(\mathrm{Ca})}\right)$ evoked by noradrenaline and caffeine by 3-6 fold.

7 Anthracene-9-carboxylic acid (A-9-C) inhibited STICs in a voltage-dependent fashion and was about 3 fold more active at $+50 \mathrm{mV}$ than at $-50 \mathrm{mV}$. A-9-C increased STIC $\tau$ and this effect was enhanced by depolarization.

8 A-9-C also inhibited caffeine-evoked $I_{\mathrm{Cl}(\mathrm{Ca})}$ but less potently than STICs and also increased the evoked $I_{\mathrm{K}(\mathrm{Ca})}$ without altering spontaneous $I_{\mathrm{K}(\mathrm{Ca})}$.

9 The results from the present work are compared with the pharmacology of other chloride conductances and the mechanism of action of the chloride channel antagonists in vascular smooth muscle is discussed.

Keywords: Pharmacological blockade; calcium-activated chloride current; vascular smooth muscle; rabbit portal vein; $\mathrm{Cl}$ channel blockers

\section{Introduction}

A calcium-activated chloride current $\left(I_{\mathrm{Cl}(\mathrm{Ca})}\right)$ was originally identified in rod segments from the salamander retina (Bader et al., 1982) and in Xenopus laevis oocytes (Miledi, 1982). Subsequently this membrane mechanism has been observed in many types of tissue including exocrine gland cells, neurones and both skeletal and cardiac muscle. $I_{\mathrm{Cl}(\mathrm{Ca})}$ was first shown in smooth muscle in the rat anococcygeus muscle where it was demonstrated that both $\alpha$-adrenoceptor and muscarinic receptor activation evokes this membrane conductance (Byrne \& Large, 1987a,b), Since then $I_{\mathrm{Cl}(\mathrm{Ca})}$ has been observed in venous (Byrne et al., 1988), and arterial smooth muscle (Amédée et al., 1990a). More recently, $I_{\mathrm{Cl}(\mathrm{Ca})}$ has been recorded in canine and guinea-pig trachea (Janssen \& Sims, 1992), rat intestine (Ohta et al., 1993) and rabbit oesophageal smooth muscle (Akbarali \& Giles, 1993). Thus it is evident that $I_{\mathrm{Cl}(\mathrm{Ca})}$ is found in many different types of smooth muscle and since it is now well established that chloride is concentrated inside the smooth muscle cell (the equilibrium potential $E_{C l}$ is between -20 and $-30 \mathrm{mV}$, see Aickin, 1990) the calcium-activated chloride conductance represents a potentially important depolarizing mechanism in smooth muscle.

In the present study we have investigated the characteristics of the inhibition of $I_{\mathrm{CI}(\mathrm{Ca})}$ by two stilbene derivatives,

\footnotetext{
1 Author for correspondence.
}

4-acetamido-4' -isothiocyanotostilbene-2,2'-disulphonic acid (SITS) and 4,4'-diisothiocyanatostilbene-2,2'-disulphonic acid (DIDS) and anthracene-9-carboxylic acid (A-9-C) on spontaneous and evoked $I_{\mathrm{Cl}(\mathrm{Ca})}$ in rabbit portal vein. These agents have a varying degree of selectivity and potency but they have been widely used in the analysis of chloride currents and quantitative data would allow pharmacological comparison of $I_{\mathrm{Cl}(\mathrm{Ca})}$ in smooth muscle with other types of chloride conductances. The present work represents the start of a programme to investigate systematically the pharmacology of $I_{\mathrm{Cl}(\mathrm{Ca})}$ in smooth muscle and in this first series of experiments we have used the most commonly used blockers of different types of chloride conductances in a wide range of tissues. It has been shown that some of these compounds do inhibit $I_{\mathrm{C}(\mathrm{Ca})}$ in smooth muscle (Baron et al., 1991; Amédée et al., 1990b) and in the present work we extend those observations and provide some indication of the mechanism of action of these chloride channel blocking compounds. Our approach to the latter problem was to investigate the action of blocking agents on the amplitude and decay time course of spontaneous transient inward currents (STICs) in rabbit portal vein cells. These random events are chloride currents, with no cation contribution, activated by calcium released from caffeine- and noradrenaline-sensitive intracellular stores (Wang et al., 1992). An interesting characteristic of STICs is that the decay of these currents is exponential and the time 
constant of decay $(\tau)$ is voltage-dependent (Hogg et al., 1993). At $-50 \mathrm{mV}$, $\tau$ was $80-90 \mathrm{~ms}$ and was increased 3 fold for a depolarization of about $120 \mathrm{mV}$. Evidence was put forward to suggest that the decay of STICs was determined by closure of calcium-activated chloride channels and that $\tau$ approximated to the channel mean open time (Hogg et al., 1993). Consequently it seemed that STICs may represent a good model for studying chloride channel antagonists in vascular smooth muscle. The results from the present work show that DIDS, SITS and A-9-C inhibit spontaneous chloride currents more readily than $I_{\mathrm{Cl}(\mathrm{Ca})}$ activated by noradrenaline and caffeine. Moreover these agents differ in their effects on the STIC $\tau$ value and their voltagedependence.

\section{Methods}

Experiments were carried out on freshly dispersed smooth muscle cells from the rabbit portal vein. Rabbits $(2-2.5 \mathrm{~kg})$ of either sex were killed by an overdose of i.v. sodium pentobarbitone and single cells were obtained by enzymatic dissociation with collagenase and papain as described previously (Hogg et al., 1993). The cells were stored in a physiological salt solution with $0.75 \mathrm{mM} \mathrm{Ca}{ }^{2+}$ at $4^{\circ} \mathrm{C}$ and were used on the same day. Whole-cell currents were measured with the perforated patch method with a patch clamp amplifier (List EPC7; List-Electronic; Darmstadt, Germany) at room temperature. In order to obtain a perforated patch, nystatin (75-200 $\mu \mathrm{g} \mathrm{ml}^{-1}$ ) was contained in the patch pipette solution. The external salt solution contained (mM): $\mathrm{NaCl}$ $126, \mathrm{KCl} 6, \mathrm{MgCl}_{2} 1.2, \mathrm{CaCl}_{2} 1.5$, HEPES 10 and glucose 11 and the $\mathrm{pH}$ was adjusted to 7.2 with $\mathrm{NaOH}$. In potassiumfree conditions, $6 \mathrm{mM} \mathrm{KCl}$ was omitted and in some experi- ments $5 \mathrm{mM}$ tetraethylammonium chloride (TEA Cl) was added to the bathing solution. The pipette solution contained (mM): $\mathrm{KCl} \mathrm{126,} \mathrm{MgCl}_{2} 1.2$, HEPES 10, glucose 11 and EGTA 0.2 . In potassium-free conditions, $126 \mathrm{mM} \mathrm{KCl}$ was replaced by an equimolar amount of $\mathrm{NaCl}$. In experiments where noradrenaline was used, $10^{-6} \mathrm{M}$ propranolol was included in the bathing solution to remove any $\beta$-adrenoceptormediated response. The recordings were usually made in static bathing solution (i.e. not continuously perfused) and the external solution was changed with a push-pull arrangement with syringes.

Some records were illustrated by playback from videotape onto a Gould brush recorder. Analysis of the time course of spontaneous transient currents was carried out on a personal computer. Signals were filted at $400 \mathrm{~Hz}$ prior to digitisation and currents were sampled at $800 \mathrm{~Hz}$ using a CED 1401 laboratory interface and captured on the hard disk of the computer. Capture and averaging of signals were performed with SIGAVG signal-averaging programme and curve fitting was done with a voltage clamp analysis programme (both Cambridge Electronic Design, Science Park, Cambridge). Exponential fit was obtained with a sum-of-squares routine From each cell 10-20 spontaneous chloride or potassium currents were averaged to obtain amplitude and time course values. In the text $n$ values refer to the number of cells used to obtain the mean determinations. The values given in the text are means \pm s.e.mean and statistical significance was estimated with either Student's $t$ test or paired $t$ test. Chemicals used were anthracene-9-carboxylic acid (A-9-C), 4,4'-diisothiocyanoto-stilbene-2,2'-disulphonic acid (DIDS), propranol and 4-acetamido-4'-isothiocyanatostilbene-2,2'disulphonic acid (SITS) (Aldrich, Gillingham, Dorset), bovine albumin (fatty acid free), caffeine, dithiothreitol, noradrenaline bitartrate, nystatin, papain (type IV), TEA Cl

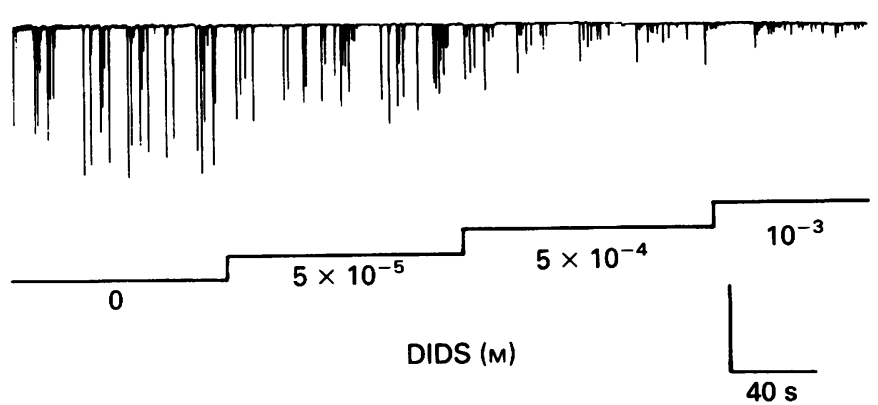

b

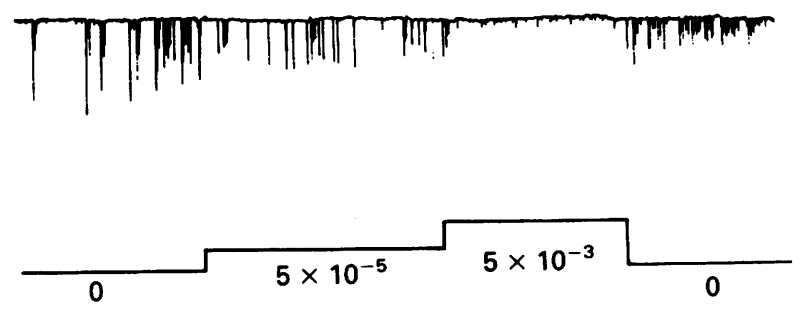

SITS (M)

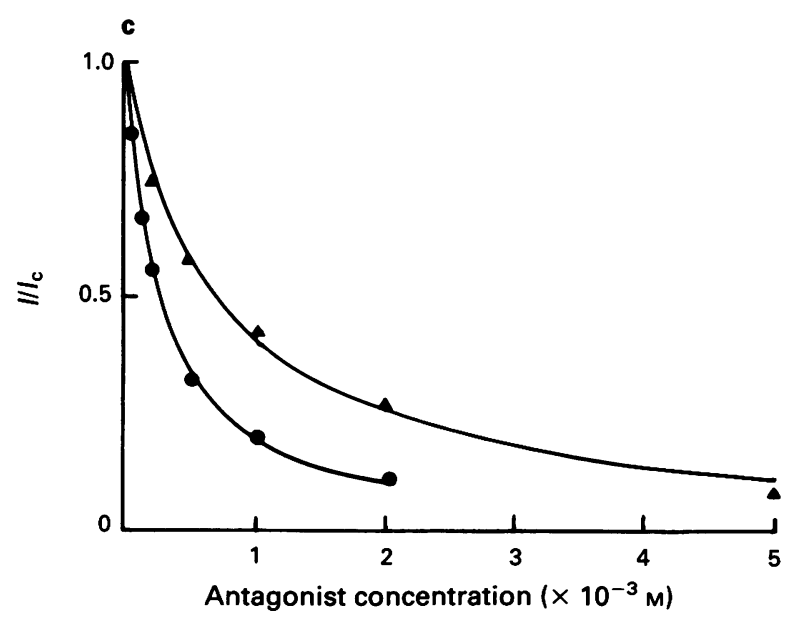

Figure 1 The effect of DIDS and SITS on STIC amplitude. DIDS (a) and SITS (b) were applied in the bathing solution at the concentrations indicated below the records. Holding potential of $-77 \mathrm{mV}$ with potassium-containing solution. The vertical calibration bar represents $50 \mathrm{pA}$ for (a) and $10 \mathrm{pA}$ for (b). In (c) the concentration-dependence of both DIDS (O) and SITS ( $\triangle$ ) is illustrated. Each point is the mean of $4-8$ cells and the s.e.means were less than $15 \%$ of the mean value but are not shown for clarity. $I$ and $I_{c}$ are the amplitude of the current in the presence and absence of the blocker, respectively. 
(all Sigma, Poole Dorset); collagenase (CLS2 $247 \mathrm{u} \mathrm{ml}^{-1}$, Worthington, Reading, Berkshire).

\section{Results}

\section{Effect of DIDS and SITS on STIC amplitude}

In the first series of experiments we investigated the effects of DIDS and SITS on spontaneous chloride currents and Figure 1 illustrates the effect of these agents on STIC amplitude. Figure $1 \mathrm{a}$ and $\mathrm{b}$ show experimental records in which DIDS and SITS reduced the amplitude of STICs in a concentration-dependent manner. The effects of both agents were rapid in onset and seemed to be maximal in the time taken to change the bathing solution (5-10 s). The degree of reversibility was rather variable and depended to some extent on the concentration used and the time for which the agent was in contact with the tissue. In general SITS was washed out more readily than DIDS and a degree of reversibility to SITS is shown in Figure 1b where on removal of this compound the amplitude of the STICs recovered a little after several minutes contact time and with a high concentration $(5 \mathrm{mM})$ of SITS. The concentration-dependence of the block by DIDS and SITS is demonstrated in Figure 1c. Hill plots of the blocking effects gave slopes of 0.9 and 0.7 for DIDS and SITS respectively and the continuous lines in Figure 1c have been drawn according to the conventional drug-receptor scheme using the Hill slope values. Presumably the non unity slopes indicate that 1 molecule binding to 1 receptor site is not a satisfactory explanation for the interaction of these blocking agents although the precise interpretation is unclear. The concentrations required to reduce the amplitude of the currents to $50 \%$ of the control value $\left(\mathrm{IC}_{50}\right)$ were $2.1 \times 10^{-4} \mathrm{M}$ and $6.4 \times 10^{-4} \mathrm{M}$ for respectively DIDS and SITS. The experiment shown in Figure 1 was carried out with potassium-containing solutions with the holding potential at -77 $\mathrm{mV}, \mathrm{E}_{\mathrm{K}}$, to remove calcium-activated potassium currents. In other experiments to study the voltage-dependence of the blockers it was necessary to remove potassium from both the pipette and external solutions (see Methods) but this experimental manipulation did not alter the potency of DIDS and SITS.

In a previous paper it was shown that the inhibition of STIC amplitude by A-9-C was voltage-dependent (Hogg et al., 1993 and see later) and we carried out experiments to ascertain whether this property was shared by DIDS and SITS. Figure 2 shows the inhibitory effect of $10^{-4} \mathrm{M}$ DIDS and $10^{-3} \mathrm{M}$ SITS at holding potentials of -50 and $+50 \mathrm{mV}$ in potassium-free solutions. From the experimental records in Figure 2 it seems that the reduction of STIC amplitude by both DIDS and SITS is similar at both test potentials and this impression is confirmed by the pooled data given in Table 1. There was no significant difference in the reduction

Table 1 Lack of voltage-dependent inhibitory effect of DIDS and SITS on STICs

\begin{tabular}{lcc}
\hline & \multicolumn{2}{c}{$\frac{I}{I_{c}}$} \\
& \multicolumn{2}{c}{ Membrane potential } \\
Blocking agent & $-50 \mathrm{mV}$ & $+50 \mathrm{mV}$ \\
DIDS $10^{-4} \mathrm{M}$ & $0.55 \pm 0.07(8)$ & $0.54 \pm 0.08$ \\
DIDS $5 \times 10^{-4} \mathrm{M}$ & $0.30 \pm 0.05(4)$ & $0.23 \pm 0.04$ \\
SITS $10^{-3} \mathrm{M}$ & $0.43 \pm 0.02(6)$ & $0.44 \pm 0.05$ \\
SITS $2 \times 10^{-3} \mathrm{M}$ & $0.29 \pm 0.05(4)$ & $0.32 \pm 0.06$
\end{tabular}

$I$ and $I_{\mathrm{c}}$ are the amplitude of STICs in the presence and absence of the blocking agent, respectively. Number of experiments given in parentheses. For abbreviations, see text. a $\quad-50 \mathrm{mV}$

$+50 \mathrm{mV}$

Control
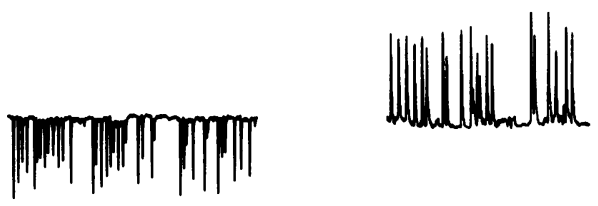

DIDS $10^{-4} \mathrm{M}$

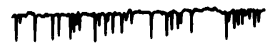

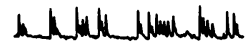

b

Control
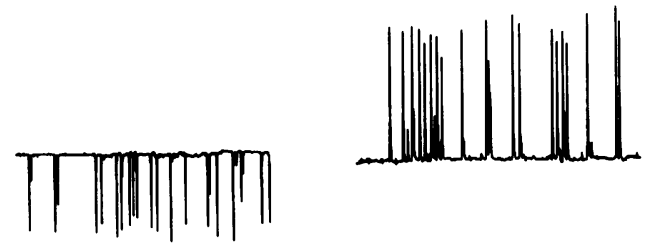

SITS $10^{-3} \mathrm{M}$
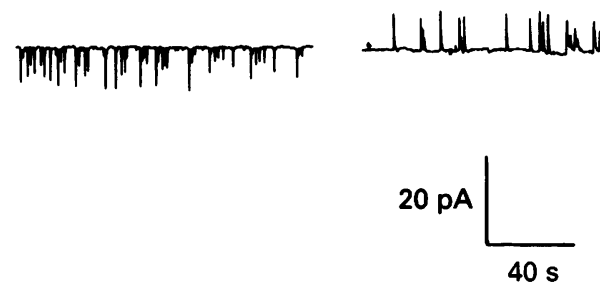

Figure 2 The inhibitory effect of DIDS and SITS on STIC amplitude at $-50 \mathrm{mV}$ and $+50 \mathrm{mV}$ holding potential. Potassium-free conditions. These are typical records in the absence and presence of the stated concentration of the blockers.

of STIC amplitude at -50 and $+50 \mathrm{mV}$ for two concentrations of both DIDS and SITS and it can be concluded that the reduction of the spontaneous chloride currents by these agents is not voltage-dependent between -50 and $+50 \mathrm{mV}$, unlike the effect of A-9-C (Hogg et al., 1993).

\section{Effect of SITS and DIDS on STIC decay time constant}

Previously it has been demonstrated that A-9-C prolonged the decay of STICs (Hogg et al., 1993) and experiments were carried out to see if SITS and DIDS also altered the STIC time course. Figure 3a illustrates the effect of $10^{-3} \mathrm{M}$ SITS on averaged STICs at holding potentials of $-50 \mathrm{mV}$ and +50 $\mathrm{mV}$ and the decays of these currents are plotted in Figure 3b. It can be seen that the reduction in STIC amplitude was accompanied by a small increase in the decay time (Figure $3 b)$. In the presence of SITS the decay of the STICs conformed to a single exponential but at $-50 \mathrm{mV}, \tau$ increased from a control value of $110 \mathrm{~ms}$ to $136 \mathrm{~ms}$ and at $+50 \mathrm{mV}, \tau$ increased from $230 \mathrm{~ms}$ to $284 \mathrm{~ms}$. Thus in the presence of SITS the decay of STICs was lengthened but was still similarly voltage-dependent. At $-50 \mathrm{mV}$ the control $\tau\left(\tau_{\mathrm{c}}\right)$ was $103 \pm 9 \mathrm{~ms}$ and in the presence of $10^{-3} \mathrm{M}$ SITS the mean $\tau$ was $135 \pm 13 \mathrm{~ms}(n=7)$. At $+50 \mathrm{mV} \tau_{\mathrm{c}}$ was $214 \pm 28 \mathrm{~ms}$ and in SITS $\tau$ was $261 \pm 29 \mathrm{~ms}$. Normalized results from several experiments are given in Table 2 and it is apparent 

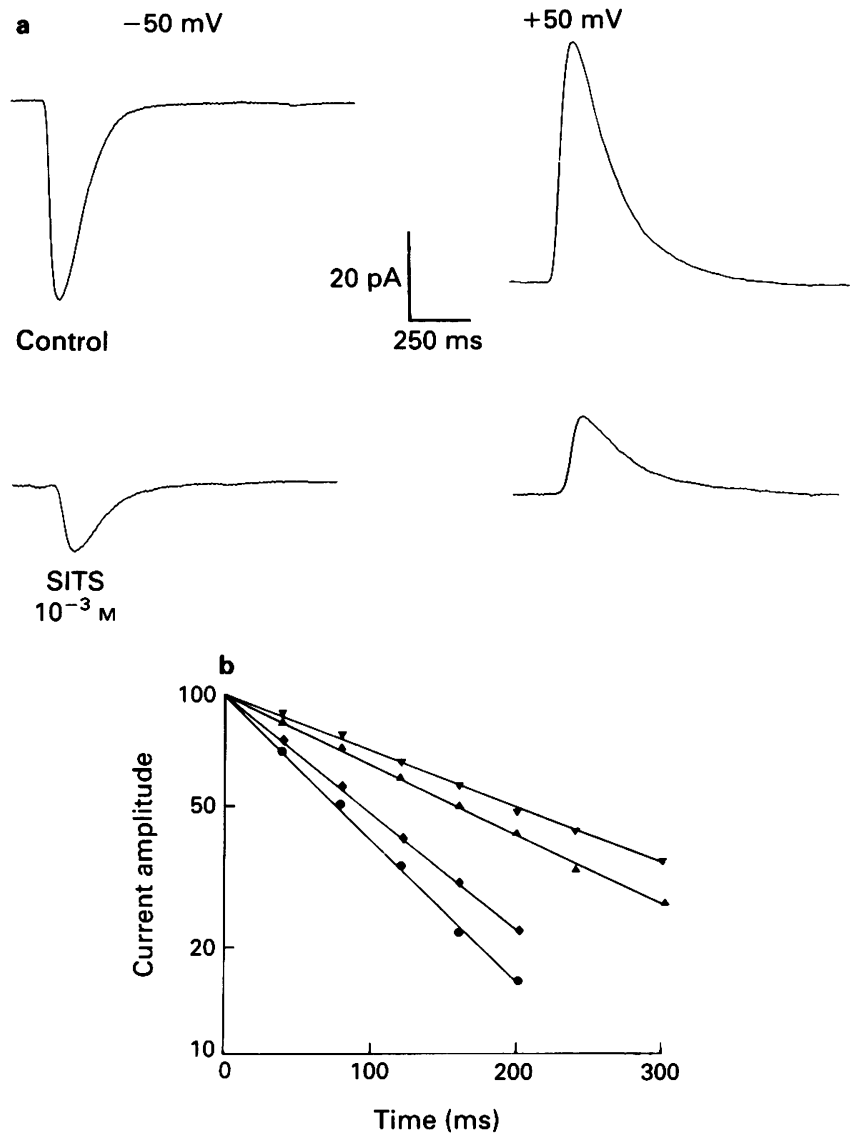

Figure 3 The effects of SITS on the STIC time course. (a) Averaged STICs at $-50 \mathrm{mV}$ and $+50 \mathrm{mV}$ in the absence and presence of $10^{-3} \mathrm{M}$ SITS. (b) The decay of the currents in (a) are plotted against time. Note the logarithmic scale of normalized current amplitude. Controls, (๑) $-50 \mathrm{mV},(\Delta)+50 \mathrm{mV}$; SITS $(\diamond)-50 \mathrm{mV},(\nabla)$ $+50 \mathrm{mV}$. Potassium-free conditions.

Table 2 Effect of blocking agents on STIC decay time constant

\begin{tabular}{lcc}
\hline & \multicolumn{2}{c}{$\frac{\tau}{\tau_{\mathrm{c}}}$} \\
& \multicolumn{2}{c}{ Membrane potential } \\
Blocking agent & $-50 \mathrm{mV}$ & $+50 \mathrm{mV}$ \\
SITS $10^{-3} \mathrm{M}$ & $1.31 \pm 0.04(7)^{*}$ & $1.21 \pm 0.06^{*}$ \\
SITS $2 \times 10^{-3} \mathrm{M}$ & $1.35 \pm 0.07(4)^{*}$ & $1.21 \pm 0.11^{*}$ \\
DIDS $10^{-4} \mathrm{M}$ & $0.75 \pm 0.05(8)^{* *}$ & $0.73 \pm 0.05^{* *}$ \\
DIDS $5 \times 10^{-4} \mathrm{M}$ & $0.82 \pm 0.05(8)^{* *}$ & $0.81 \pm 0.04^{* *}$ \\
DIDS $10^{-3} \mathrm{M}$ & $0.78 \pm 0.09(4)^{* *}$ & $0.81 \pm 0.08^{* *}$
\end{tabular}

${ }^{*} P<0.01,{ }^{* *} P<0.05$ represent statistically different values of the time constant of decay in the presence of the drug $(\tau)$ compared to the value in the absence of the drug $\left(\tau_{\mathrm{C}}\right)$ that SITS produced a similar increase in $\tau$ at -50 and at $+50 \mathrm{mV}$. However, an interesting observation was that $2 \times$ $10^{-3} \mathrm{M}$ SITS produced no further increase in $\tau$ compared to $10^{-3} \mathrm{M}$ SITS (Table 2) even though the higher concentration produced a greater reduction in the STIC amplitude than the lower concentration (see Figure 1c). Thus the maximal effect on STIC $\tau$ was achieved at lower concentrations of SITS than on STIC amplitude.

Figure $4 \mathrm{a}-\mathrm{c}$ demonstrates the effect of $5 \times 10^{-4} \mathrm{M}$ DIDS on the time course of averaged STICS in one experiment at a holding potential of $-50 \mathrm{mV}$. In Figure $4 \mathrm{c}$ the trace in the presence of DIDS has been scaled up and the currents in Figure $4 \mathrm{a}$ and $\mathrm{b}$ have been superimposed. It can be seen that the rise times are identical but in the presence of DIDS the STIC decays more rapidly. In Figure 4d it is shown that in the presence of the blocking agent the STIC decays exponentially with a $\tau$ value of $81 \mathrm{~ms}$ compared to the control $\tau$ of $105 \mathrm{~ms}$. In eight experiments, $5 \times 10^{-4} \mathrm{M}$ DIDS reduced $\tau$ from a control value of $94 \pm 10 \mathrm{~ms}$ to $77 \pm 11 \mathrm{~ms}$ at -50 $\mathrm{mV}$. At $+50 \mathrm{mV}$ the corresponding values were $220 \pm 26 \mathrm{~ms}$ (control) and $180 \pm 19 \mathrm{~ms}$ (DIDS). The normalized data in Table 2 illustrate that the reduction in $\tau$ by DIDS was not voltage-dependent as the degree of shortening of the $\tau$ values was similar at $-50 \mathrm{mV}$ and $+50 \mathrm{mV}$. Also it was found that low concentrations reduced both STIC $\tau$ and amplitude whereas with higher concentrations of DIDS the increased reduction of STIC amplitude was not accompanied by further shortening of the STIC decay time.

\section{Effect of SITS and DIDS on spontaneous potassium currents}

STICs are activated by calcium released from an intracellular caffeine-sensitive store (Wang et al., 1992) and it is possible that blocking agents might affect STICs by an action on the intracellular calcium store. This possibility can be tested directly by studying the action of these compounds on spontaneous transient outward (potassium) currents (STOCs) which are also activated by calcium released from the caffeine-sensitive store (Benham \& Bolton, 1986).

Figure $5 \mathrm{a}$ and $\mathrm{b}$ show the effect of high concentrations of SITS and DIDS on STOCs recorded with potassium-containing solutions at a holding potential of $0 \mathrm{mV}$ (i.e. close to $\mathrm{E}_{\mathrm{Cl}}$ so that these currents are pure calcium-activated potassium currents). Figure $5 \mathrm{c}$ and $\mathrm{d}$ are averaged STOCs from Figure $5 \mathrm{a}$ and $\mathrm{b}$ and it is apparent from this Figure and the pooled data from several experiments shown in Table 3 that the blocking agents had no effect on any of the measured parameters of STOCs. Therefore it can be concluded that it is unlikely that the blocking effect of DIDs and SITS on STICs is mediated by an effect on the intracellular calcium store.

\section{Effect of SITS and DIDS on evoked $I_{\mathrm{Cl}(\mathrm{Ca})}$}

It was of interest to study the effect of the chloride channel antagonists on $I_{\mathrm{Cl}(\mathrm{Ca})}$ evoked by either noradrenaline or caffeine for comparison with their effects on spontaneous currents. Typical records of these experiments are shown in Figure $6 \mathrm{a}$ and $\mathrm{b}$ and it can be seen that there is a concentration-dependent inhibition of both noradrenaline- and

Table 3 The effect of antagonists on the characteristics of STOCs

$\begin{array}{lrcc}\text { Blocking agent } & \text { Amplitude } & \text { Rise time } & \text { Half-decay time } \\ \text { SITS } 10^{-3} \mathrm{M} & 1.0 \pm 0.11(4) & 1.01 \pm 0.02 & 0.99 \pm 0.11 \\ \text { SITS } 2 \times 10^{-3} \mathrm{M} & 0.88 \pm 0.09(4) & 0.99 \pm 0.05 & 0.89 \pm 0.09 \\ \text { DIDS } 10^{-4} \mathrm{M} & 1.0 \pm 0.01(4) & 1.12 \pm 0.18 & 0.98 \pm 0.09 \\ \text { DIDS } 5 \times 10^{-4} \mathrm{M} & 1.08 \pm 0.08(4) & 1.06 \pm 0.13 & 1.08 \pm 0.08 \\ \text { DIDS } 10^{-3} \mathrm{M} & 1.01 \pm 0.09(3) & 1.11 \pm 0.06 & 1.08 \pm 0.08\end{array}$

The numbers given are the ratios of the values in the presence of the drug compared to the control values. 

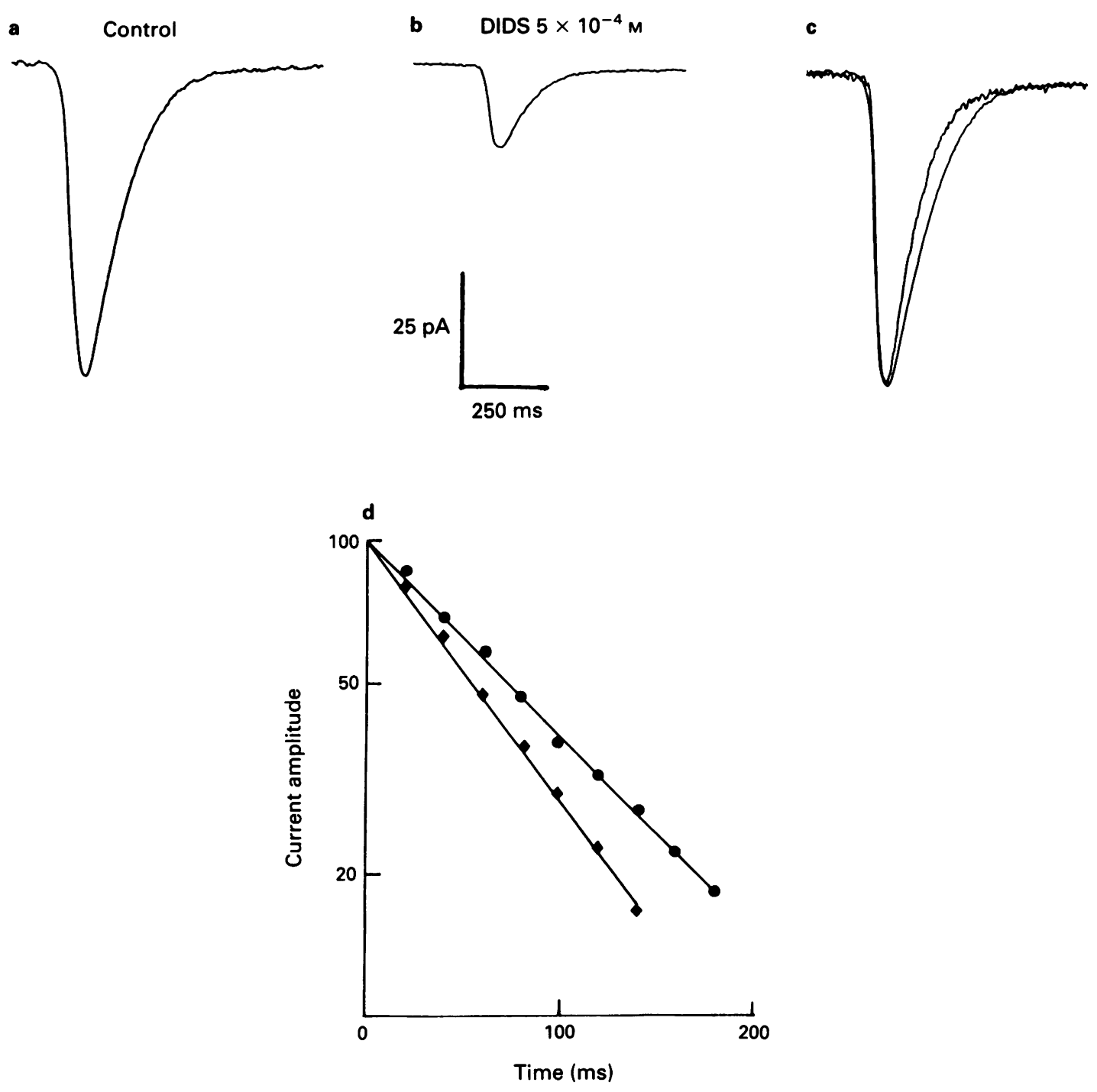

Figure 4 The effects of DIDS on the STIC time course. Records (a) and (b) are averaged STICs recorded at $-50 \mathrm{mV}$ in potassium-free solutions in the absence and presence of $5 \times 10^{-4} \mathrm{M}$ DIDS, respectively. In (c) the current in (b) is scaled up and superimposed over the control STIC in (a). The current with the faster decay was recorded in $5 \times 10^{-4} \mathrm{M}$ DIDS. In (d) the decay of the currents in (a) and (b) are plotted semi-logarithmically and the $\tau$ values were $105 \mathrm{~ms}$ (control, 0 ) and $81 \mathrm{~ms}$ (DIDS, $\bullet$ ).

caffeine-induced $I_{\mathrm{Cl}(\mathrm{Ca})}$. There did not seem to be any difference in the effects of the antagonists on caffeine- or noradrenaline-evoked currents and therefore the results with caffeine and noradrenaline were pooled. As with STICs there was some reversibility of the inhibitory effect if the contact time was not too great (Figure 6b). The concentration-effect of the inhibitory effect against evoked $I_{\mathrm{Cl}(\mathrm{Ca})}$ is shown graphically in Figure $6 \mathrm{c}$ and the $\mathrm{IC}_{50}$ values for DIDS and SITS were estimated to be $7.5 \times 10^{-4} \mathrm{M}$ and $1.8 \times 10^{-3} \mathrm{M}$, respectively. A notable consequence of these results is that the $\mathrm{IC}_{50}$ values against evoked currents are about $2-3$ times higher than the respective values against spontaneous currents (DIDS, $2 \times 10^{-4} \mathrm{M}$ and SITS, $6.4 \times 10^{-4} \mathrm{M}$ ). This difference in effect can be seen quite clearly in many of the records shown. For example compare the effect of $10^{-3} \mathrm{M}$ SITS on the evoked current in Figure 6a with the action on the spontaneous current in Figure 3a. An interesting observation is that $5 \times 10^{-4} \mathrm{M}$ SITS appeared to potentiate induced $I_{\mathrm{CI}(\mathrm{Ca})}$ although this effect was not statistically significant.

\section{Effect of DIDS and SITS on evoked calcium-activated potassium currents}

The difference in potency of the blocking agents against evoked and spontaneous $I_{\mathrm{Cl}(\mathrm{Ca})}$ was a surprising and interest- ing result and therefore we decided to investigate the effect of SITS and DIDS on caffeine- and noradrenaline-evoked calcium-activated potassium currents $\left(I_{\mathrm{K}(\mathrm{Ca})}\right)$ which are mediated by the same intracellular calcium stores that are responsible for noradrenaline-induced $I_{\mathrm{Cl}(\mathrm{Ca})}$ (Wang \& Large, 1991b). An additional benefit of these experiments is that it has been shown that noradrenaline stimulates both $I_{\mathrm{C}(\mathrm{Ca})}$ and $I_{\mathrm{K} \text { (Ca) }}$ by an action of the $\alpha_{1}$-adrenoceptor (Wang \& Large, 1991a) and thus possible interference with the pharmacological recognition site can be appraised by studying the effect of the blocking agents on $I_{\mathrm{K}(\mathrm{Ca})}$. Figure $7 \mathrm{a}$ shows that bath application of $10^{-3} \mathrm{M}$ SITS produced a marked increase in the amplitude of the noradrenaline-evoked $I_{\mathrm{K}(\mathrm{Ca})}$. This enhancement of the potassium current was sustained in the continued presence of SITS and was partially reversible after washout of the compound. The enhancement of $I_{\mathrm{K}(\mathrm{Ca})}$ was concentration-dependent as the increase of the evoked $I_{\mathrm{K}(\mathrm{Ca})}$ was 3.8 \pm 1.7 fold and $5.7 \pm 1.6$ fold for respectively $10^{-3} \mathrm{M}$ and $2 \times 10^{-3} \mathrm{M}$ SITS ( $n=5$ for both concentrations). The increase of $I_{\mathrm{K}(\mathrm{Ca})}$ was observed whether noradrenaline or caffeine was used to evoke the current. Figure $7 \mathrm{~b}$ illustrates that $10^{-4} \mathrm{M}$ DIDS produced a large increase in the amplitude of the caffeine-evoked $I_{\mathrm{K}(\mathrm{Ca})}$. DIDS $10^{-4} \mathrm{M}$ and $10^{-3} \mathrm{M}$ increased the amplitude of the evoked $I_{\mathrm{K} \text { (Ca) }}$ by $3.0 \pm 0.6$ and $4.0 \pm 0.5$ times, respectively ( $n=6$ for each concentration). 
a

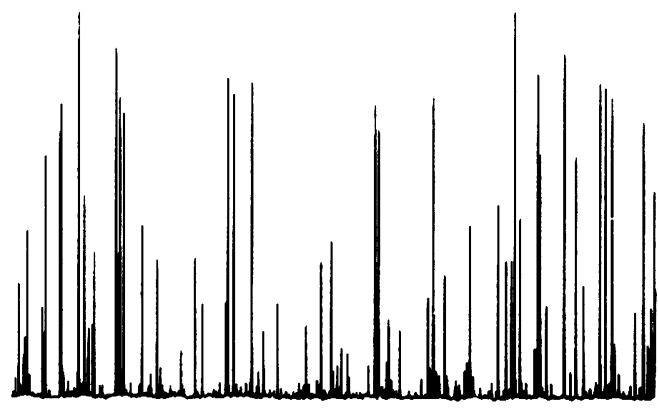

SITS $2 \times 10^{-3} \mathrm{M}$

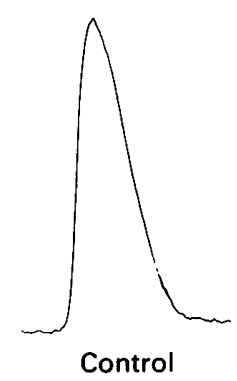

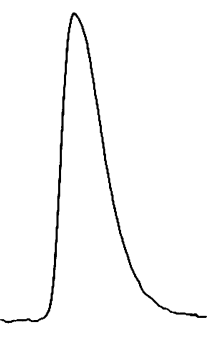

SITS $2 \times 10^{-3} \mathrm{M}$
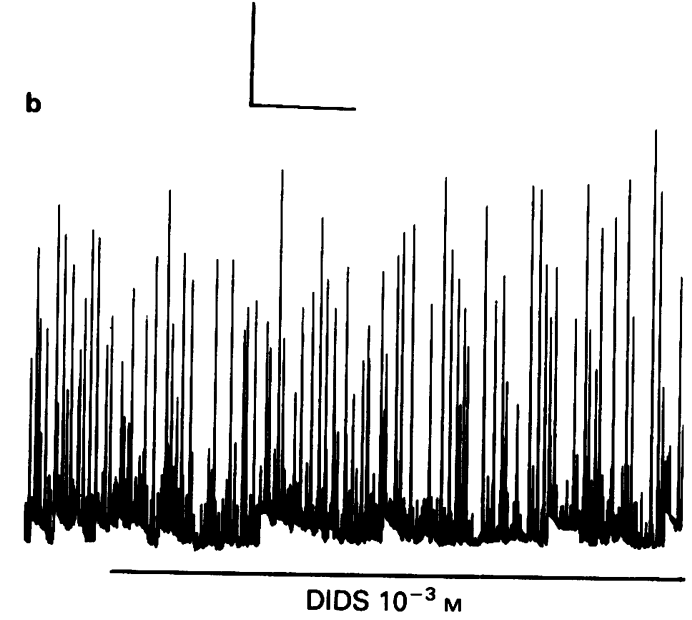

d

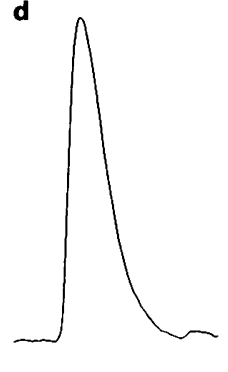

Control

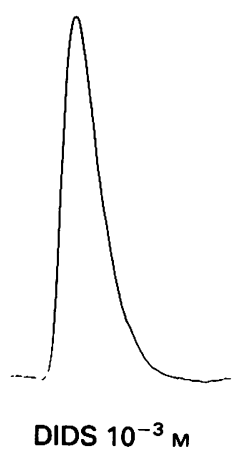

Figure 5 The effect of SITS and DIDS on STOCs. (a) and (b) are experimental records in which SITS and DIDS were applied as indicated by the horizontal bar; (c) and (d) show averaged STOCs taken from the traces in (a) and (b). Vertical calibration, $100 \mathrm{pA}$ for (a) and (c) and $50 \mathrm{pA}$ for (b) and (d). Horizontal calibration, $40 \mathrm{~s}$ for (a) and (b) and $100 \mathrm{~ms}$ for (c) and (d). Holding potential of $0 \mathrm{mV}$ with potassium-containing solutions.

a

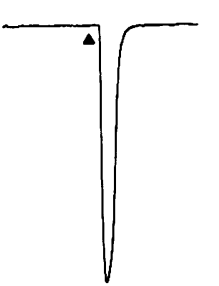

Control<smiles>C=C=CCC</smiles>

$\overline{\text { Caffeine }}$

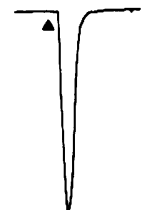

SITS $10^{-3} \mathrm{M}$
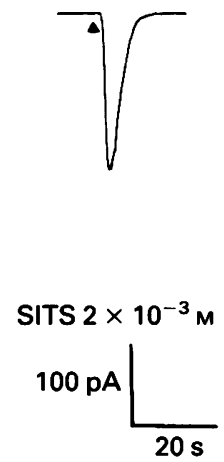

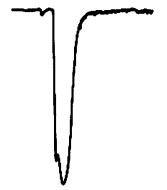

Caffeine
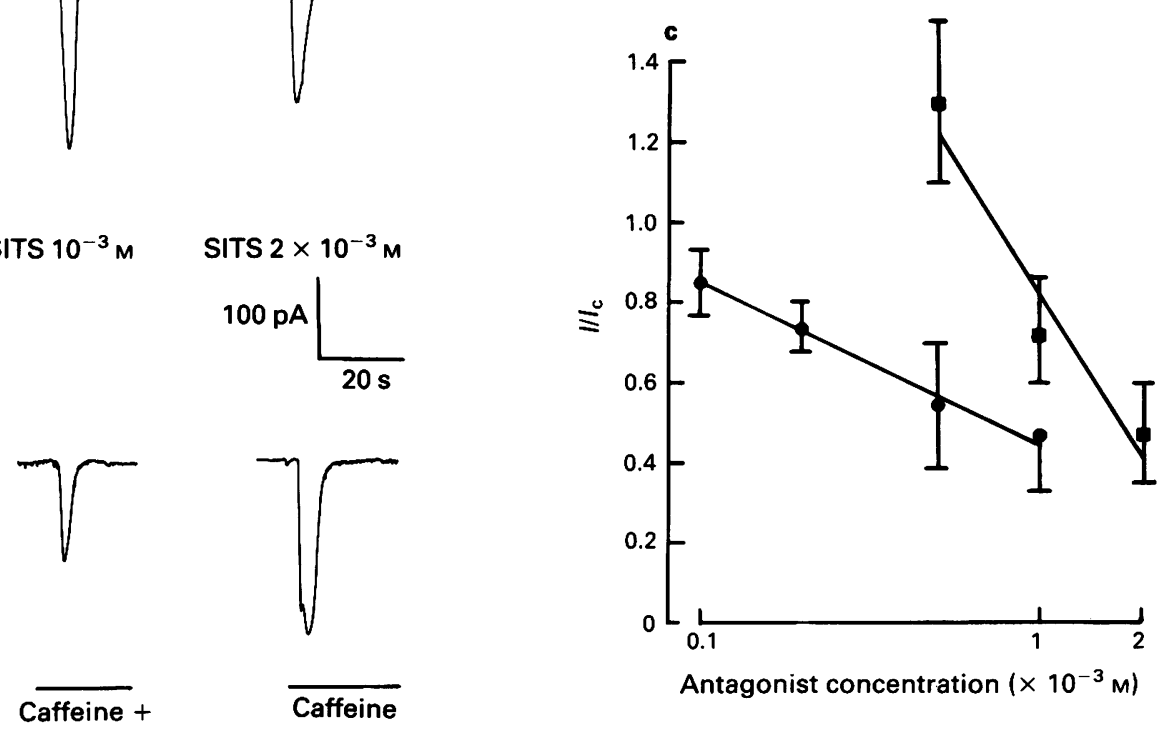

Antagonist concentration $\left(\times 10^{-3} \mathrm{M}\right)$

Figure 6 The effect of DIDS and SITS on $I_{\text {(Y) }}$ evoked by noradrenaline and caffeine. In (a), the currents were induced by ionophoretic application of noradrenaline $(50 \mathrm{nA}$ for $200 \mathrm{~ms})$ indicated by the arrowheads. In (b) $I_{\mathrm{C}(\mathrm{Ca})}$ was activated by bath-applied caffeine $(5 \mathrm{mM})$. In these experiments the gap in the records represents about $5 \mathrm{~min}$. Holding potential, - $50 \mathrm{mV}$ in potassium-free solutions. In (c), the concentration-effect relationship is plotted. $I$ and $I_{c}$ are the current amplitudes in the presence and absence of the antagonists respectively and a ratio of $I / I_{\mathrm{c}}$ greater than 1.0 represents potentiation. Each point is the mean of 4-6 cells and the lines were drawn by eye: (a) SITS; (O) DIDS. 
a<smiles>C1CCCCCCCCCCC1</smiles>
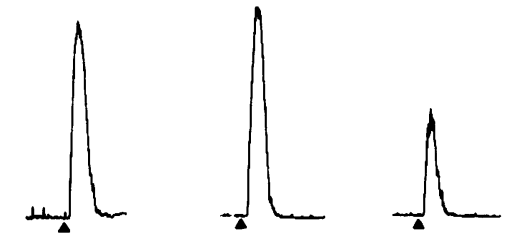

Control
200 pA

b

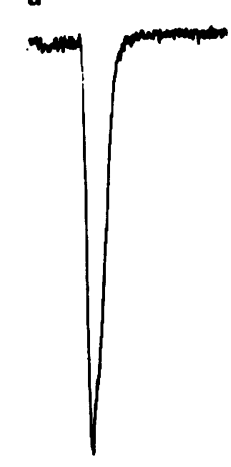

Control

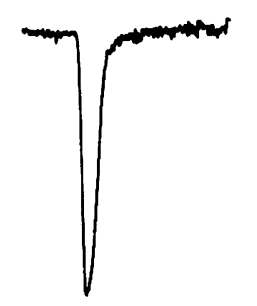

$\overline{A-9-C 5 \times 10^{-4}}$
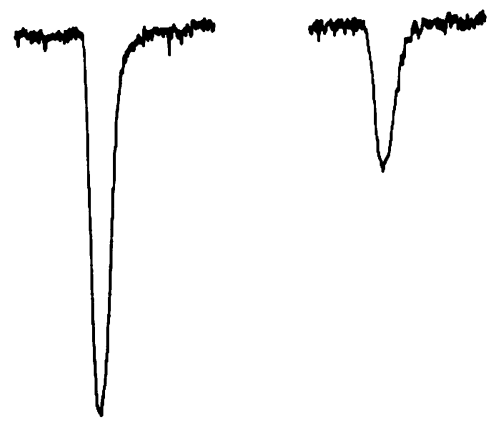

noradrenaline and caffeine. In (a) noradrenaline was applied by ionophoresis at arrowheads $(50 \mathrm{nA}$ for $400 \mathrm{~ms})$. The middle records were obtained 3 and $6 \mathrm{~min}$ after $10^{-3} \mathrm{M}$ SITS had been added to the bathing solution and the wash was recorded $8 \mathrm{~min}$ after the antagonist had been removed. In (b) $10^{-3} \mathrm{M}$ caffeine was bath-applied to activate the currents before, 1 and $4 \mathrm{~min}$ after $10^{-4} \mathrm{M}$ DIDS had been included in the external solution. Horizontal calibration bar, $10 \mathrm{~s}$ for (a) and $20 \mathrm{~s}$ for (b). Holding potential of $0 \mathrm{mV}$ in potassiumcontaining solutions.
The effect of A-9-C on spontaneous and evoked $\mathrm{I}_{C I(C)}$

Preliminary data from Hogg et al. (1993) showed that $2 \times$ $10^{-4} \mathrm{M}$ A-9-C produced a voltage-dependent decrease in STIC amplitude and increase in STIC decay time constant. on spontaneous and evoked calcium-activated currents. The estimated IC 50 values of A-9-C against STICs at +50 and $-50 \mathrm{mV}$ were $9 \times 10^{-5} \mathrm{M}$ and $3 \times 10^{-4} \mathrm{M}$, respectively and therefore the potency of A-9-C on STIC amplitude increased 3.3 fold for a $100 \mathrm{mV}$ change in membrane potential. The voltage-dependence of the effect of A-9-C on amplitude was

Figure 7 The action of SITS and DIDS on $I_{\mathrm{K}(\mathrm{Ca})}$ evoked by 
accompanied by a voltage-dependent increase in STIC decay time. With $10^{-4} \mathrm{M}$ A-9-C $\tau$ was increased from a control value of $91 \pm 9 \mathrm{~ms}$ to $101 \pm 16 \mathrm{~ms}$ at $-50 \mathrm{mV}(n=7) . \tau_{\mathrm{c}}$ was $201 \pm 16 \mathrm{~ms}$ at $+50 \mathrm{mV}$ and $\tau$ was $496 \pm 52 \mathrm{~ms}$ in the presence of $10^{-4} \mathrm{M}$ A-9-C. Thus the increase in $\tau$ produced by $10^{-4} \mathrm{M}$ A-9-C was $1.09 \pm 0.09$ fold at $-50 \mathrm{mV}$ and $2.47 \pm 0.27$ fold at $+50 \mathrm{mV}$. With $2 \times 10^{-4} \mathrm{M} \mathrm{A-9-C}$, $\tau$ increased by $1.20 \pm 0.07$ times at $-50 \mathrm{mV}$ and $2.65 \pm 0.13$ times at $+50 \mathrm{mV}(n=7$, data from Table 2, Hogg et al., 1993). Therefore as with DIDS and SITS, reduction of amplitude by A-9-C was not associated with a change in $\tau$ throughout the full dose-response curve. It is possible that this characteristic might have been unmasked with higher concentrations of A-9-C but an unfavourable signal to noise ratio precluded the analysis. Other experiments with potassium-containing solutions at $0 \mathrm{mV}$ demonstrated that $2 \times$ $10^{-4} \mathrm{M}, 5 \times 10^{-4} \mathrm{M}$ and $10^{-3} \mathrm{M}$ A-9-C $(n=3$ for each concentration) had no effect on STOCs.

In the light of the results with DIDS and SITS we carried out further experiments to ascertain the effect of A-9-C on evoked $I_{\mathrm{Cl}(\mathrm{Ca})}$ and $I_{\mathrm{K}(\mathrm{Ca})}$. The traces in Figure 8 show the results from 2 experiments. In potassium-free conditions at a holding potential of $-50 \mathrm{mV}$ A-9-C produced a concentration-dependent decrease of the caffeine-evoked $I_{\mathrm{Cl}(\mathrm{Ca})}$ (Figure 8a). In 7 experiments, $5 \times 10^{-4} \mathrm{M}$ and $10^{-3} \mathrm{M} \mathrm{A}-9-\mathrm{C}$ decreased the evoked $I_{\mathrm{Cl}(\mathrm{Ca})}$ to $0.55 \pm 0.1$ and $0.42 \pm 0.07$ of the control currents, respectively. Assuming a linear relationship between the degree of inhibition and concentration in this concentration-range, the estimated $\mathrm{IC}_{50}$ is about $6.5 \times 10^{-4} \mathrm{M}$ A-9-C. This value against evoked currents is about double the $\mathrm{IC}_{50}\left(3 \times 10^{-4} \mathrm{M}\right.$ at $\left.-50 \mathrm{mV}\right)$ for A-9-C against STICs. In potassium-containing solutions at a holding potential of $0 \mathrm{mV}, 10^{-3} \mathrm{M}$ A-9-C increased the amplitude of the caffeineevoked $I_{\mathrm{K}(\mathrm{C})}$ which was only partially reversible after washout of A-9-C (Figure 8b). The increase in the amplitude of the evoked $I_{\mathrm{K}(\mathrm{Ca})}$ by $5 \times 10^{-4} \mathrm{M}$ and $10^{-3} \mathrm{M}$ A-9-C was $1.84 \pm 0.07$ times and $2.08 \pm 0.34$ times, respectively $(n=4$ for each concentration). Therefore it can be concluded that A-9-C enhanced the amplitude of the evoked $I_{\mathrm{K}(\mathrm{Ca})}$ in the same concentration-range which reduced $I_{\mathrm{Cl}(\mathrm{Ca})}$.

\section{Discussion}

The two main aims of the present work were first to characterize pharmacologically $I_{\mathrm{Cl}(\mathrm{Ca})}$ in the rabbit portal vein for comparison with other chloride conductances. Secondly, we attempted to gain an insight into the mechanism of action of some commonly-used chloride channel antagonists on $I_{\mathrm{Cl}(\mathrm{Ca})}$ in vascular smooth muscle. It was hoped that such experiments might reveal important characteristics associated with blockade of $I_{\mathrm{Cl}(\mathrm{Ca})}$ in smooth muscle. There have been only a few quantitative studies on the pharmacological blockade of $I_{\mathrm{Cl}(\mathrm{Ca})}$ in smooth muscle and many reports are limited to a single concentration of an antagonist. Nevertheless, we will compare the $\mathrm{IC}_{50}$ values of the antagonists on STICs from the present work with previous published data. Baron et al. (1991) investigated the effects of DIDS and A-9-C on $I_{\mathrm{Cl}(\mathrm{Ca})}$ evoked by either caffeine or the influx of calcium through voltage-dependent calcium channels in the rat portal vein. They reported $\mathrm{IC}_{50}$ values of $16.5 \mu \mathrm{M}$ for DIDS and $117 \mu \mathrm{M}$ for A-9-C. The values for A-9-C in the previous paper and the present investigation $\left(3 \times 10^{-4} \mathrm{M}\right.$ against STICs) are comparable. However, the earlier value for DIDS is an order less then the value against STICs from the present work $(2.1 \times$ $\left.10^{-4} \mathrm{M}\right)$. Against noradrenaline- or caffeine-evoked $I_{\mathrm{Cl}(\mathrm{Ca})}$ the estimated $\mathrm{IC}_{50}$ for DIDS was even higher $\left(7.5 \times 10^{-4} \mathrm{M}\right)$ in our study (see later). There is no obvious explanation for the increased potency of DIDS observed in the rat portal vein compared to the rabbit portal vein except for a difference in species and experimental conditions. In rat intestine it was shown that $0.1 \mathrm{mM}$ DIDS and $0.5 \mathrm{~mm}$ SITS reduced $I_{\mathrm{Cl}(\mathrm{Ca})}$ by $50 \%$ and $39 \%$, respectively (Ohta et al., 1993) and therefore these results are comparable to the present data. Akbarali \& Giles (1993) also reported that $300 \mu \mathrm{M}$ A-9-C reduced $I_{\mathrm{C}(\mathrm{Ca})}$ in rabbit oesophageal smooth muscle but the data are far too limited at present to make comparisons with the present results. In other tissues it was claimed that $10^{-4} \mathrm{M}$ DIDS blocked totally $I_{\mathrm{Cl}(\mathrm{Ca})}$ in rabbit ventricular myocytes (Zygmunt \& Gibbons, 1991). Since this concentration reduced the STIC amplitude to only $55 \%$ of the control value there may be a difference between the pharmacology of $I_{\mathrm{Cl}(\mathrm{Ca})}$ in ventricle and venous muscle. In cystic fibrosis epithelial cells, $0.5 \mathrm{mM}$ DIDS reduced $I_{\mathrm{Cl}(\mathrm{Ca})}$ by $87 \%$ (Anderson \& Welsh, 1991) and 1-2 mM SITS produced a significant but incomplete block of $I_{\mathrm{Cl}(\mathrm{Ca})}$ in avian neurones (Bader et al., 1987) and cultured pituitary cells (Korn \& Weight, 1987). The degree of inhibition of $I_{\mathrm{Cl}(\mathrm{Ca})}$ by the stilbene derivatives in these tissues are similar to the reduction of STICs in the rabbit portal vein produced by the same concentrations of the antagonists in the present study. These findings indicate a similar sensitivity of $I_{\mathrm{Cl}(\mathrm{Ca})}$ to DIDS and SITS in epithelial, neuronal and smooth muscle cells.

Some interesting observations arise from comparison with other types of chloride conductances. For example it appears that DIDs does not inhibit the adenosine $3^{\prime}: 5^{\prime}$-cyclic monophosphate (cyclic AMP)-mediated chloride current in cystic fibrosis airway epithelia (Anderson \& Welsh, 1991). In cardiac myocytes, $100 \mu \mathrm{M}$ SITS and DIDS actually enhanced the isoprenaline-induced chloride current which is also mediated by cyclic AMP (Harvey, 1993) although this conductance is sensitive to A-9-C (Harvey \& Hume, 1989). In contrast, the voltage-gated chloride conductance in rat cultured astrocytes is significantly inhibited by low concentrations of DIDS $(20 \mu \mathrm{M})$ but is insensitive to A-9-C (Gray \& Ritchie, 1986). Consequently it is apparent that different chloride conductances have quite disparate sensitivities to the stilbene derivatives and A-9-C and although these agents are not potent, their use helps to establish the pharmacological profiles of different chloride conductances. It should be noted that many useful channel blocking chemicals possess low potency and have $\mathrm{IC}_{s_{0}}$ values in the range of $0.1-10 \mathrm{~mm}$ (e.g. tetraethylammonium on potassium channels).

The study of the blocking agents on the spontaneous chloride currents showed that the three compounds had quite distinctive effects on STICs. None of the inhibitors in the concentrations used altered the amplitude, rise time or halfdecay of the spontaneous calcium-activated potassium currents which indicates that the blockers did not act on the intracellular calcium store (which is the primary source of calcium for triggering both STOCs and STICs) or on the potassium channels. It is possible that these agents inhibited the STICs by blocking the binding site with which calcium combines to open the chloride channel. Little is known about this site and we cannot rule out this possibility but there is some evidence that A-9-C, at least, inhibited the chloride currents by blocking the channel itself. A-9-C produced a voltage-dependent reduction in amplitude and lengthening of the decay phase of the spontaneous chloride currents which was readily reversible. Voltage-dependent reduction of a membrane current is normally interpreted to mean that molecules of the blocking agent bind to a receptor site within the membrane electrical field. The rapid onset of effect of A-9-C suggests that the most likely locus for its action is the channel pore itself and thus the data suggest that as the inside of the membrane is made more positive, A-9-C is driven into the chloride channel to produce a greater block. A corollary of this hypothesis is that it is the negatively charged ion of A-9-C that is responsible but further experiments with $\mathrm{pH}$ changes are necessary to confirm this conclusion.

There is less evidence to suggest that DIDS and SITS act as channel blockers. These agents produced only a small change in the STIC $\tau$ value and a clear concentrationdependence was not obtained. The fact that they did not block the currents completely, that the Hill plots are non- 
linear and the poor reversibility indicate that these compounds have a more complicated action. It is intriguing that DIDS and SITS are inhibitors of both anion transporters and chloride channels. It is tempting to speculate that they bind to something in common in both these membrane mechanisms, perhaps the anion recognition site.

An unexpected finding was that all three blocking agents inhibited spontaneous chloride currents more readily than the response evoked by caffeine and noradrenaline. The $\mathrm{IC}_{50}$ values were 2-4 fold higher for the evoked compared to the spontaneous currents. A possible explanation for this discrepancy is that there are two classes of calcium-activated chloride channels in rabbit portal vein cells. However, since STICs and evoked $I_{\mathrm{Cl}(\mathrm{Ca})}$ are triggered by calcium from the same intracellular store and the permeability ratios of various anions for spontaneous and evoked currents are similar (Wang \& Large, 1991a; Wang et al., 1992), we feel that this proposal is unlikely. A more attractive hypothesis is that in addition to blocking $I_{\mathrm{Cl}(\mathrm{Ca})}$ in the sarcolemma, the agents may also increase the amount of calcium that is released from the sarcoplasmic reticulum in response to the agonists caffeine and noradrenaline which may tend to counteract the blockade of $I_{\mathrm{CI}(\mathrm{Ca})}$. All of the compounds produced a marked

\section{References}

AICKIN, C.C. (1990). Chloride transport across the sarcolemma of vertebrate smooth and skeletal muscle. In Chloride Channels and Carriers in Nerve, Muscle and Glial cells. ed. Alvarez-Leefmans, F.J. \& Russell, J.M. New York: Plenum Press.

AKBARALI, H.I. \& GILES, W.R. (1993). $\mathrm{Ca}^{2+}$ and $\mathrm{Ca}^{2+}$-activated $\mathrm{Cl}^{-}$ currents in rabbit oesophageal smooth muscle. J. Physiol., 460, 117-133.

AMÉDÉE, T., BENHAM, C.D., BOLTON, T.B., BYRNE, N.G. \& LARGE W.A. (1990a). Potassium chloride and non-selective cation conductances opened by noradrenaline in rabbit ear artery cells. $J$. Physiol., 423, 551-568.

AMÉDÉE, T., LARGE, W.A. \& WANG, Q. (1990b). Characteristics of chloride currents activated by noradrenaline in rabbit ear artery cells. J. Physiol., 428, 501-516.

ANDERSON, M.P. \& WELSH, M.J. (1991). Calcium and cAMP activate different chloride channels in the apical membrane of normal and cystic fibrosis epithelia. Proc. Natl. Acad. Sci. U.S.A., 88, 6003-6007.

BADER, C.R., BERTRAND, D. \& SCHLICHTER, R. (1987). Calciumactivated chloride current in cultured sensory and parasympathetic quail neurones. J. Physiol., 394, 125-148.

BADER, C.R., BERTRAND, D. \& SCHWARTZ, E.A. (1982). Voltageactivated and calcium-activated currents studied in solitary rod inner segments from the salamander retina. J. Physiol., 331, 253-284.

BARON, A., PACAUD, P., LOIRAND, G., MIRONNEAU, C. \& MIRONNEAU, J. (1991). Pharmacological block of $\mathrm{Ca}^{2+}$-activated $\mathrm{Cl}^{-}$ current in rat vascular smooth muscle cells in short term primary culture. Pflügers Archiv., 419, 553-558.

BENHAM, C.D. \& BOLTON, T.B. (1986). Spontaneous transient outward currents in single visceral and vascular smooth muscle cells of the rabbit. J. Physiol., 381, 385-406.

BRAYDEN, D.J., KROUSE, M.E., LAW, T. \& WINE, J.J. (1993). Stilbenes stimulate $\mathrm{T} 85 \mathrm{Cl}^{-}$secretion by elevating $\mathrm{Ca}^{2+}$. Am. J. Physiol., 264, G325-G333.

BYRNE, N.G. \& LARGE, W.A. (1987a). Action of noradrenaline on single smooth muscle cells freshly dispersed from the rat anococcygeus muscle. J. Physiol., 389, 513-525.

BYRNE, N.G. \& LARGE, W.A. (1987b). Membrane mechanism associated with muscarinic receptor activation in single cells freshly dispersed from the rat anococcygeus muscle. Br. J. Pharmacol., 92, 371-379. increase in the amplitude of $I_{\mathrm{K}(\mathrm{Ca})}$ evoked by caffeine and noradrenaline. Since there was no effect on the calciumactivated potassium currents which were triggered by the spontaneous release of calcium, the increase of the evoked$I_{\mathrm{K}(\mathrm{Ca})}$ is presumably due to an increased release of calcium from the sarcoplasmic reticulum rather than a direct effect on the potassium channels. No direct measurement of calcium was made in the present work but recently it has been shown in T84 cells that stilbene derivatives elevate the intracellular calcium concentration which activates an anion conductance (Brayden et al., 1993). Also it has been shown that DIDS and SITS open the Ca-release channel of the sarcoplasmic reticulum in skeletal muscle (Kawasaki \& Kasai, 1989). If this action occurred in smooth muscle it is possible that chloride channel antagonists increased the amount of caffeine- and noradrenaline-evoked release of calcium from the sarcoplasmic reticulum which tended to overcome to some extent the blockade of $I_{\mathrm{Cl}(\mathrm{Ca})}$ in the sarcolemma produced by the same compounds.

This work was supported by the Medical Research Council and The Wellcome Trust.
BYRNE, N.G. \& LARGE, W.A. (1988). Membrane ionic mechanisms activated by noradrenaline in cells isolated from the rabbit portal vein. J. Physiol., 404, 557-573.

GRAY, P.T.A. \& RITCHIE, J.M. (1986). A voltage-gated chloride conductance in rat cultured astrocytes. Proc. $R$. Soc. B., 228, 267288.

HARVEY, R.D. (1993). Effects of stilbenedisulfonic acid derivatives on the cAMP-regulated chloride current in cardiac myocytes. Pfiügers Arch., 422, 436-442.

HARVEY, R.D. \& HUME. J.R. (1989). Autonomic regulation of a chloride current in heart. Science, 244, 983-985.

HOGG, R.C., WANG, Q. \& LARGE, W.A. (1993). Time course of spontaneous calcium-activated chloride currents in smooth muscle cells from the rabbit portal vein. J. Physiol., 464, 15-31.

JANSSEN, L.J. \& SIMS, S.M. (1992). Acetylcholine activates nonselective cation and chloride conductances in canine and guineapig tracheal myocytes. J. Physiol., 453, 197-218.

KAWASAKI. T. \& KASAI, M. (1989). Disulfonic stilbene derivatives open the $\mathrm{Ca}^{2+}$ release channel of sarcoplasmic reticulum. $J$. Biochem., 106, 401-405.

KORN. S.J. \& WEIGHT, F.F. (1987). Patch-clamp study of the calcium-dependent chloride current in AtT-20 pituitary cells. $J$. Neurophysiol., 58, 1431-1451.

MILEDI. R. (1982). A calcium-dependent outward current in Xenopus laevis oocytes. Proc. R. Soc. B., 215, 491-497.

OHTA. T., ITO, S. \& NAKAZATO, Y. (1993). Chloride currents activated by caffeine in rat intestinal smooth muscle cells. J. Physiol., 465, 149-162.

WANG, Q.. HOGG, R.C. \& LARGE, W.A. (1992). Properties of spontaneous inward currents in smooth muscle cells isolated from the rabbit portal vein. J. Physiol., 451, 535-537.

WANG, Q. \& LARGE, W.A. (1991a). Noradrenaline-evoked cation conductance recorded with the nystatin whole-cell method in rabbit portal vein cells. J. Physiol., 435, 21-39.

WANG, Q. \& LARGE, W.A. (1991b). Modulation of noradrenalineinduced membrane currents by papaverine in rabbit vascular smooth muscle cells. J. Physiol., 439, 501-512.

ZYGMUNT, A.C. \& GIBBONS, W.R. (1991). Calcium-activated chloride current in rabbit ventricular myocytes. Circ. Res., 68, 424437. 